and yet will also be accepted as a credible, citable contribution to the literature. Surely this deserves to be applauded.

Matthew Cockerill

BioMed Central Ltd, 34-42 Cleveland Street, London W1P 6LE, UK

\section{How reliable is science information on the web?}

Sir - Until recently, the dissemination of scientific information has largely been regulated by publishers via peer review and by librarians through their purchases of journals. With the advent of the WorldWide Web, however, the publication of science has been democratized. Although this 'deregulation' will speed the flow of valuable information around the world, a negative side effect may be the increased exposure of students and the public to misleading or biased science, or to opinion masquerading as science. Here, we report on the overall reliability of websites that purvey scientific information.

Our results are sobering. Although the web is increasingly used as a source of scientific information, the quality of the information provided by many of the most easily accessed sites is poor. To gain an understanding of the quality of information on the web, we performed searches for the terms 'evolution' (EV), 'genetically modified organism' (GMO) and 'endangered species' (ES) using Northernlight.com, the search engine with the broadest reported coverage of the web ${ }^{1}$.

The first 500 websites retrieved for each topic were examined sequentially by two referees until each had independently reviewed approximately 60 sites containing information pertinent to the topic. These informative sites were scored as 'inaccurate' if they contained information that was factually incorrect, 'misleading' if they misinterpreted science or blatantly omitted facts supporting an opposing position, and 'unreferenced' if they presented information without any peer-reviewed references.

For EV, only $12 \%$ ( 59 of 500 ) of the websites examined were considered informative by both referees. For GMO and ES, 46\% (64 of 140) and 28\% (55 of 200) of sites, respectively, were considered informative. Of informative sites, the proportion that were judged inaccurate ranged from 10\% for GMO to 34\% for EV (Fig. 1). Likewise, the proportion of informative sites scored as misleading ranged from $20 \%$ for ES to $35 \%$ for EV. A much higher proportion of sites were unreferenced (more than $48 \%$ for each category), but the presence or absence of references does not necessarily correspond with the other scores.

Overall agreement values for the refer-

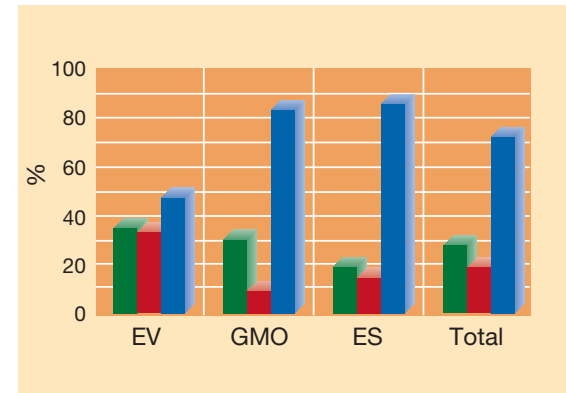

Figure 1 Percentage of informative websites reviewed for the search topics 'evolution' (EV), 'genetically modified organism' (GMO) and 'endangered species' (ES) that were misleading (green bars), inaccurate (red bars), and unreferenced (blue bars). Data are averaged across referees.

ees' scores for the categories of 'inaccurate' and 'misleading' were $87.8 \%$ for EV sites, $82.8 \%$ for GMO sites and $73.6 \%$ for ES sites. Because the presence or absence of peer-reviewed citations is not subjective, no agreement values were calculated for this category.

Our results indicate that science-related websites have serious liabilities. Many sites purporting to contain science are simply presentations of opinion or social commentary. And the presence of peer-reviewed citations, normally a sign of reliability, does not necessarily reflect the quality of the information presented. Nonetheless, we recognize the substantial advantages conferred by global access to the huge stores of information on the web, particularly for those who might otherwise have limited access to scientific resources.

One promising strategy for such users is the exploitation of recently established portals that provide links to sites that have been reviewed by scientists for accuracy, relevance and currency ${ }^{2-4}$. These portals, if widely used, also offer a means of establishing peer review as the guiding principle for evaluating science on the web ${ }^{5}$.

Eva S. Allen, John M. Burke, Mark E. Welch, Loren H. Rieseberg

Department of Biology, Indiana University, $1001 \mathrm{E}$. 3rd Street, Bloomington, Indiana 47405, USA

1. Lawrence, S. \& Giles, C. L. Nature 400, 107-109 (1999).

2. Encyclopedia Britannica, Inc. www.britannica.com (4 October 1999).

3. SciCentral. www.scicentral.com/index.html (4 October 1999).

4. Science NetLinks. www.sciencenetlinks.com/science/index. shtml (4 October 1999).

5. Fainzilber, M. Nature 401, 111 (1999).

\section{Where nuclear weapons come before basic needs}

Sir - In his review of the books by Itty Abraham and Michael Foot, Brahma Chellaney chastises Abraham for "his commitment to one side" of the nuclear debate in India which supposedly "weakens his arguments" (Nature 401, 113-114; 1999). Although Abraham's sympathies may well lie on the side of India's growing anti-nuclear movement, Chellaney is very much on the other side.

Chellaney is a member of India's National Security Advisory Board and an author of the draft "nuclear doctrine", which calls for "sufficient nuclear weapons to inflict destruction and punishment" ${ }^{\text {.1 }}$. So it comes as no surprise that he puts a positive gloss on the history of India's nuclear weapons, and paints an inaccurate picture of Abraham's book.

Chellaney persists in describing India's 1974 nuclear test as a "peaceful explosion". Such semantic evasions no longer carry any weight, if they ever did. Even Raja

Ramanna, former chairman of India's Atomic Energy Commission and the leader of the team that conducted the test, described it as "a prototype weapon".

Chellaney also attempts to suggest that India is unique among nuclear weapons states in having straddled the "nuclear fence" for a quarter of a century while having a democratic debate on whether it should "go nuclear". A less self-serving description would be that India spent decades building a ladder to climb over this imaginary nuclear fence and, when it came time to decide whether to jump down to the other side, a handful of people made the decision, as has always been the case in Indian nuclear policy ${ }^{3}$.

Abraham's book shows how Indian scientists used the ideologies of national security and national development to transform a small scientific laboratory into a full-blown weapons complex. His work demonstrates how the combination of science, ideology and the power of the state can be a recipe for disaster as much in the Third World as in the first and second.

Abraham's real achievement is to reveal the thinking of India's élite, which places nuclear weapons above providing even the most basic necessities to a large proportion of the country's citizens.

It is at this level, the right of ordinary people to make meaningful choices about their lives in an informed and democratic way, that Abraham is taking sides. It is a side he shares with Foot, but one far removed from the cabals of "the wizards of Armageddon" who make nuclear-weapons policy around the world.

\section{Zia Mian, M. V. Ramana}

Center for Energy and Environmental Studies, Princeton University, Princeton,

New Jersey 08544, USA

\footnotetext{
1. National Security Advisory Board Draft Report on Indian Nuclear Doctrine http://www.indianembassy.org/policy/CTBT/ nuclear_doctrine_aug_17_1999.html

2. Ramanna, R. Years of Pilgrimage 100 (Viking, New Delhi, 1991).

3. Ramana, M. V. Precis IX, No. 3, pp. 1 \& 21-25 (1998).
} 